\title{
Medical marijuana laws and workplace fatalities in the United States
}

\section{Authors: D. Mark Anderson, Daniel I. Rees, and Erdal Tekin}

NOTICE: this is the author's version of a work that was accepted for publication in International Journal of Drug Policy. Changes resulting from the publishing process, such as peer review, editing, corrections, structural formatting, and other quality control mechanisms may not be reflected in this document. Changes may have been made to this work since it was submitted for publication. A definitive version was subsequently published in International Journal of Drug Policy, VOL\# 60, (October 2018) DOI\# 10.1016/j.drugpo.2018.07.008.

Anderson, D. Mark, Daniel I. Rees, and Erdal Tekin. "Medical marijuana laws and workplace fatalities in the United States." International Journal of Drug Policy 60 (October 2018): 33-39. DOI:10.1016/j.drugpo.2018.07.008.

Made available through Montana State University's ScholarWorks scholarworks.montana.edu 


\title{
Medical Marijuana Laws and Workplace Fatalities in the United States
}

\author{
D. Mark Anderson, Ph.D.* \\ Department of Agricultural Economics and Economics \\ Montana State University \\ Email: dwight.anderson@montana.edu
}

Daniel I. Rees, Ph.D.

Department of Economics

University of Colorado Denver

Email: daniel.rees@ucdenver.edu

Erdal Tekin, Ph.D.

School of Public Affairs

American University

Email: tekin@american.edu

June 2018

Word count: 3,163

\footnotetext{
* Corresponding author. Address: Department of Agricultural Economics and Economics, Montana State University, P.O. Box 172920, Bozeman, MT 59717-2920. Phone: 406-366-0921.
} 


\section{Medical Marijuana Laws and Workplace Fatalities in the United States}

Aims: The aim of this research was to determine the association between legalizing medical marijuana and workplace fatalities.

Design: Repeated cross-sectional data on workplace fatalities at the state-year level were analyzed using a multivariate Poisson regression.

Setting: To date, 29 states and the District of Columbia have legalized the use of marijuana for medicinal purposes. Although there is increasing concern that legalizing medical marijuana will make workplaces more dangerous, little is known about the relationship between medical marijuana laws (MMLs) and workplace fatalities.

Participants: All 50 states and the District of Columbia for the period 1992-2015.

Measurements: Workplace fatalities by state and year were obtained from the Bureau of Labor Statistics. Regression models were adjusted for state demographics, the unemployment rate, state fixed effects, and year fixed effects.

Findings: Legalizing medical marijuana was associated with a $19.5 \%$ reduction in the expected number of workplace fatalities among workers aged 25-44 (incident rate ratio [IRR], .805; 95\% CI, .662-.979). The association between legalizing medical marijuana and workplace fatalities among workers aged 16-24, although negative, was not statistically significant at conventional levels. The association between legalizing medical marijuana and workplace fatalities among workers aged 25-44 grew stronger over time. Five years after coming into effect, MMLs were associated with a $41.1 \%$ reduction in the expected number of workplace fatalities (IRR, .663; 95\% CI, .482-.912). MMLs that listed pain as a qualifying condition or allowed collective cultivation were associated with larger reductions in fatalities among workers aged 25-44 than those that did not.

Conclusions: The results provide evidence that legalizing medical marijuana improved workplace safety for workers aged 25-44. Further investigation is required to determine whether this result is attributable to reductions in the consumption of alcohol and other substances that impair cognitive function, memory, and motor skills. 


\section{INTRODUCTION}

Although marijuana remains illegal under federal law, 29 states and the District of Columbia have passed laws legalizing its use for medicinal purposes. ${ }^{1}$ Medical marijuana laws (hereafter MMLs) remove state-level penalties for using and possessing marijuana for medical purposes. Patients are required to obtain approval or certification from a physician, and physicians who recommend marijuana to their patients are immune from criminal prosecution.

Increasingly, concerns are being raised over the potential impact of MMLs on workplace safety. ${ }^{2-5}$ As a backdrop to these concerns, there are important legal issues surrounding workplace safety and the use of medical marijuana that remain unresolved. For instance, in many states it is unclear whether employers can impose sanctions on registered medical marijuana patients who test positive for tetrahydrocannabinol (the psychoactive component in marijuana), or whether insurance companies can claim marijuana as the cause of injury or death in the workplace. ${ }^{6-8}$

There is strong evidence that legalizing medical marijuana leads to a decrease in the price of marijuana and an increase in its consumption, presumably due to diversion from the medical to the recreational market. ${ }^{9-11}$ However, the association between legalization and workplace safety could, in theory, be negative or positive. On the one hand, extensive research has demonstrated that there are important short-term effects of marijuana use on psychomotor performance and cognition that could lead to more on-the-job accidents, including impairments in memory function, information processing, hand-eye coordination, and reaction times. ${ }^{12-15}$ On the other hand, previous studies have found that the legalization of medical marijuana leads to substantial reductions in the consumption of alcohol, opioids and other substances, ${ }^{9,}{ }^{16-19}$, which could lead to safer workplaces and fewer accidents. 
Drawing on data at the state-year level collected by the Bureau of Labor Statistics for the period 1992-2015, the relationship between legalizing medical marijuana and workplace fatalities was examined. Multivariate Poisson regression analysis was used to adjust for demographics, income, the unemployment rate, legalization of recreational marijuana, decriminalization of marijuana, state fixed effects, and year fixed effects. No previously published study has examined the relationship between MMLs and workplace fatalities.

\section{METHODS}

Panel data on workplace fatalities at the state-year level came from Census of Fatal Occupational Injuries (CFOI). These data are produced by the Occupational Safety and Health Statistics (OSHS) program, which is administered by the Bureau of Labor Statistics (BLS). The CFOI provides counts of all fatal work injuries occurring in the U.S. during each calendar year. The OSHS program uses diverse state, federal, and independent data sources to identify, verify, and describe fatal work injuries, ensuring that counts are as complete and accurate as possible. The CFOI data are publicly available from the BLS for the period under study, 1992-2015, and

have been used by previous researchers interested in the determinants of workplace saftey. ${ }^{20-22}$ Total workplace fatality counts by state and year, as well as counts for different age groups are available. Twenty-four years multiplied by 51 (50 states and the District of Columbia) yielded a total of 1,224 observations for analysis. Data on nonfatal workplace injuries and illnesses are also available from the BLS. However, due to the well-known under-reporting issues with these data, we opted to focus solely on workplace fatalities. ${ }^{23-26}$

Information on the state-level legalization of medical marijuana is reported in Table 1. During the period under study, 24 states and the District of Columbia adopted MMLs, although 
medical marijuana programs were not yet operational in four of these states (Maryland, Minnesota, New Hampshire, and New York). Sixteen of the remaining 20 states permitted patients to register on the basis of pain, which (because pain cannot be objectively confirmed) could encourage recreational use. ${ }^{27}$ Twelve of the 20 states that legalized medical marijuana during the period under study prohibited collective cultivation, also known as "group growing", either by limiting caregivers to one patient or restricting where and how marijuana can be grown. Law enforcement authorities assert that there is more diversion from the medicinal market to the recreational market in states that allow collective cultivation. ${ }^{28}$

Multivariate Poisson regression analysis was used to estimate the association between an indicator (i.e., a 0/1 variable) of medical marijuana legalization, $M M L$, and the expected number of workplace fatalities in a given state and year. An advantage of the Poisson model is that the inclusion of fixed effects does not lead to an incidental parameters problem. ${ }^{29}$ The natural logarithm of the number of workers was used as an offset variable. If a MML came into effect after January 1, it was coded as a fraction for that year (e.g., it was coded as 0.5 if the law came into effect on July 1). Incident rate ratios (IRRs) were considered statistically significant if their 95\% confidence interval (CI) did not include the value of one. We corrected standard errors (which were used to calculate CIs and p-values) for clustering at the state level. ${ }^{30}$

Following previous studies in this area of research ${ }^{9-11,16-17,19}, 50$ state indicators were included as covariates in the regression analysis. Their inclusion on the right-hand side of the regression model accounted for the influence of time-invariant factors at the state level (i.e., state "fixed effects") such as rules and regulations pertaining to workplace safety and ensured that estimates of the association between legalizing medical marijuana and workplace fatalities were identified using only within-state variation over time. Again, following previous studies in this 
area of research ${ }^{9-11,16-17,19}, 23$ year indicators were included to account for year-to-year changes in workplace fatalities that were common across all 50 states and the District of Columbia due to, for instance, changes in federal regulations or technology. Given the inclusion of state and year fixed effects, the regression model represents a difference-in-differences specification, which relies on the parallel trends assumption being satisfied. In Figure 1, we plot workplace fatality trends for the treated and control states prior to MMLs going into effect. The trend for control states was created based on 50 random assignments of the MMLs. We find little evidence of systematic differences between the pre-MML trends for treated versus control states.

Estimated IRRs were also adjusted for within-state changes over time in demographics (percent of the population white, percent black, and percent over the age of 18), per-capita income, the unemployment rate, the legalization of recreational marijuana, and the decriminalization of marijuana. There is evidence that workplace accidents are generally procyclical $^{31}$, while the effects of legalizing recreational marijuana and decriminalizing marijuana could be similar to the effects of legalizing medical marijuana. Information on MMLs, whether the use of recreational marijuana was legal, and the decriminalization of marijuana came from a variety of published sources. ${ }^{1,32-33}$ The state unemployment rate and per-capita income came from the Bureau of Labor Statistics and the Bureau of Economic Analysis, respectively. ${ }^{34-35}$ Means of workplace fatalities and the covariates are reported in Table 2.

Several extensions of the basic multivariate Poisson regression model described above were also estimated. Specifically, the expected number of workplace fatalities was replaced by the expected number of workplace fatalities for the following age groups: 16-24, 25-44, 45-64, and $65+$. Previous studies provide evidence that legalizing medical marijuana has larger effects on marijuana consumption among young adults than among adolescents or older adults. ${ }^{10,36-38} \mathrm{In}$ 
addition, regressions were run allowing the association between MMLs and workplace fatalities to vary according to whether pain was included as a qualifying condition and whether collective cultivation was allowed. Critics of legalizing medical marijuana contend that including chronic or severe pain as a qualifying condition encourages recreational use by registered patients, ${ }^{27}$ while there is evidence that the effect of MMLs on substance use is strongest when collective cultivation is allowed. ${ }^{9}, 19,39$ Finally, estimates of the association between MMLs and workplace fatalities were allowed to vary according to the time elapsed since implementation to account for delays in patient registration and the opening of dispensaries. These estimates were used to produce an event-study figure, which allowed an examination of pre-treatment trends in workplace fatalities. There is evidence that the effect of MMLs on substance use is weakest immediately after implementation, becoming steadily stronger thereafter. ${ }^{9-10,16}$

\section{RESULTS}

The association between legalizing medical marijuana and total workplace fatalities, although negative, was not statistically significant at conventional levels (Table 3). By contrast, legalizing medical marijuana was associated with a $19.5 \%$ reduction in the expected number of workplace fatalities among workers aged 25-44 (IRR, .805; 95\% CI, .662-.979) after adjusting for the covariates listed in Table 2, state fixed effects, and year fixed effects. This negative association was robust to including state-specific linear trends in the model. The association between MMLs and workplace fatalities among workers aged 16-24, although negative, was not statistically significant. Likewise, the association between MMLs and workplace fatalities among workers aged 45 and over was negative but not statistically significant at the $5 \%$ level. The final two columns in Table 3 show a negative association between MMLs and workplace 
fatalities for both male and female workers, but neither estimate is statistically significant at conventional levels.

The negative association between legalizing medical marijuana and workplace fatalities among workers aged 25-44 was strongest if pain was included as a qualifying condition (Table 4, Panel I). Specifically, legalizing medical marijuana was associated with a $19.8 \%$ reduction in the expected number of workplace fatalities among workers aged 25-44 (IRR, .802; 95\% CI, .657-.978) if pain was included as a qualifying condition; if pain was not included as a qualifying condition, the association between legalizing medical marijuana and workplace fatalities was not statistically significant (IRR, .980; 95\% CI, .859-1.12).

The negative association between MMLs and workplace fatalities among workers aged 25-44 was stronger in states that allowed collective cultivation than in states that did not (Table 4, Panel II). Specifically, legalizing medical marijuana was associated with a $20.5 \%$ reduction in the expected number of workplace fatalities among workers aged 25-44 (IRR, .795; 95\% CI, .651-.971) if collective cultivation was allowed; if collective cultivation was not allowed, the association between legalizing medical marijuana and workplace fatalities was not statistically significant (IRR, 1.03; 95\% CI, .832-1.27).

To study effects over time, we replace the $M M L$ indicator with three lead indicators, an indicator for the year of the law change (year 0), and five lag indicators. Consistent with the parallel trends assumption, there is no evidence of an association between MMLs and workplace fatalities among workers aged 25-44 prior to year 0 after adjusting for the covariates listed in Table 2, state fixed effects, and year fixed effects (Figure 2). After implementation, the negative association between MMLs and workplace fatalities among workers aged 25-44 gained strength over time. In the first four years after implementation, the association between legalization and 
workplace fatalities was relatively small and not statistically significant. For instance, one year after implementation the IRR was 1.01 [95\% CI, .903-1.14], and three years after implementation the IRR was .861 [95\% CI, .741-1.00]. However, five or more years after implementation, the association between MMLs and workplace fatalities was negative, larger in absolute magnitude, and statistically significant. Specifically, legalizing medical marijuana was associated with a $33.7 \%$ reduction in the expected number of workplace fatalities among workers aged 25-44 (IRR, .663; 95\% CI, .482-.912).

\section{DISCUSSION}

MMLs protect patients from criminal prosecution for smoking marijuana and for consuming it in oils, pills, and edibles. However, the use of medical marijuana in the workplace is generally not protected. Several states (e.g., Colorado, Michigan, Oregon, Washington) have ruled that employers may discipline employees or terminate their employment following a positive drug test because MMLs are not intended to address employment issues. ${ }^{6-7}$ Although some MMLs explicitly protect employees from termination due to a positive drug test, employers and insurance companies continue to argue in court that the use of medical marijuana violates zero-tolerance drug policies and compromises workplace safety. ${ }^{4,8}$

Unresolved legal issues notwithstanding, it is clear that workplace injuries impose substantial costs on society. In 2015, the latest year for which statistics are available, there were a total of 4,836 fatal on-the-job injuries in the United States. ${ }^{40}$ The causes of these injuries are myriad, ranging from homicide, to motor vehicle accidents, to electrocution, to being crushed by machinery. ${ }^{40}$ Given their frequency, any estimate of the cost of legalizing medical marijuana is likely to be inaccurate if workplace fatalities are not taken into account. 
Legalizing the use of medical marijuana should unambiguously lead to an increase in the consumption of marijuana. ${ }^{41-42}$ By contrast, the association between legalization and workplace safety could, in theory, be either negative or positive. Marijuana use impairs memory function, information processing, hand-eye coordination, and reaction times ${ }^{12-15}$, all of which could plausibly result in more on-the-job accidents and workplace fatalities. Indeed, a number of epidemiological studies provide evidence of a positive association between marijuana use and the likelihood of being involved in a motor vehicle accident ${ }^{43}$, one of the leading causes of onthe-job injury in the United States. ${ }^{40}$

However, other studies show that the legalization of medical marijuana is associated with substantial reductions in the consumption of alcohol, opioids and other substances. ${ }^{9}{ }^{16-19}$ For instance, Anderson et al. found that legalization of medical marijuana was associated with a $5 \%$ reduction in beer sales ${ }^{9}$, while Bachhuber et al. found that legalization of medical marijuana was associated with a $20 \%$ to $33 \%$ decrease in deaths involving opioids. ${ }^{16}$ Because the use of alcohol at work is associated with a substantial increase in the risk of injury ${ }^{44-45}$, and because nonhabitual opioid use slows reflexes and impairs cognitive functioning ${ }^{46}$, the enactment of MMLs could, in theory, make workplaces safer.

Traffic fatalities, the abuse of other substances, suicides, and crime are among the costs of legalizing medical marijuana considered by previous researchers. ${ }^{9,11,16,47-50}$ The current study, however, is the first to examine the association between MMLs and workplace fatalities. Using data from the BLS and a multivariate Poisson regression model, a negative association between MMLs and fatalities among workers aged 25-44 was found after adjusting for state demographics, the unemployment rate, the decriminalization of marijuana, the legalization of recreational marijuana, state fixed effects, and year fixed effects. 
The negative association between MMLs and workplace fatalities among workers aged 25-44 was robust to including state-specific linear trends in the model, suggesting that it cannot be explained by slowly evolving, but difficult-to-measure factors at the state level such as attitudes or health behaviors. ${ }^{16}$ The association between MMLs and workplace fatalities among workers aged 16-24, although negative, was not statistically significant. Likewise, the association between MMLs and workplace fatalities among workers above the age of 44 was not statistically significant. This general pattern of results is not surprising given that previously published research suggests that young adults respond to the legalization of medical marijuana by consuming substantially less alcohol, ${ }^{9,19}$ while any response to legalizing medical marijuana on the part of teenagers and older adults has been difficult to isolate from year-to-year fluctuations in substance use. ${ }^{9-10,19,36-38}$

Two studies provide evidence that MMLs passed in the 1990s and early 2000s led to higher enrollment rates and greater marijuana consumption than did newer "medicalized" medical marijuana programs. ${ }^{23,51}$ Consistent with these findings, the negative association between MMLs and workplace fatalities among adults aged 25-44 was stronger in states that included severe or chronic pain as a qualifying condition. Consistent with the argument that diversion to the recreational market can be limited by prohibiting home growing and limiting caregivers to one patien $\mathrm{t}^{28}$, the negative association between MMLs and workplace fatalities among adults aged 25-44 was stronger in states that allowed collective cultivation. Finally, consistent with the parallel trends assumption, there was no evidence of any association between MMLs and workplace fatalities among workers aged 25-44 in the years leading up to implementation. However, the negative association between MMLs and workplace fatalities gradually became larger in magnitude after implementation. 
This study has several limitations that deserve mention. First, the data are at the state as opposed to the individual level. Access to detailed individual-level data collected by the BLS would allow us to explore who precisely was affected by MMLs and would allow us to describe the nature of their injuries. Access to individual-level data could also improve the precision of the estimates and would allow us to explore the association between MMLs and workplace fatalities in specific industries or occupations by age (e.g., young adults working in mining, young adults working in construction, etc.). The negative associations between MMLs and workplace fatalities found for other age groups (i.e., workers aged 16-24, workers aged 45-64, and workers over the age of 64) were not statistically significant. Using individual-level data would allow us to adjust for other factors (e.g., marital status, educational attainment, occupation) and could produce more precise estimates of these associations.

Second, the estimates provided in Tables 3 and 4 demonstrate a negative association between MMLs and workplace fatalities among adults aged 25-44, but it is not clear why this negative association exists. This negative association could be the result of workers responding to the legalization of medical marijuana by reducing their use of other substances (e.g., alcohol and prescription opioids). It is also possible that this negative association is due to other, often more-difficult-to-document, effects of THC. For instance, drivers under the influence of THC appear to take fewer risks ${ }^{2}$, which could reduce fatal accidents among, for instance, truck drivers and other transportation workers. Consistent with the argument that workers are healthier, and perhaps less prone to being involved in an accident, the legalization of medical marijuana has been linked to fewer sickness-related absences from work. ${ }^{52}$ In the absence of detailed data on drug and alcohol use by workers involved in accidents, it will be difficult to distinguish between these various potential mechanisms. 
Third, and finally, the inclusion of state fixed effects in our regression models accounted for the influence of time-invariant factors that could be correlated with MMLs and workplace fatalities. However, it is possible that there were difficult-to-observe factors at the state level that changed over time and led both to the adoption of MMLs and to reductions in workplace fatalities. Although there was no evidence of reductions in workplace fatalities prior to the adoption of MMLs (Figure 2), if these factors changed at the same time as the legalization of medical marijuana, their influence would have been difficult to detect.

\section{CONCLUSION}

Although 29 states and the District of Columbia have passed laws legalizing marijuana for medicinal use, there is a dearth of evidence on the relationship between medical marijuana and workplace safety. The current study is the first to explore the effects of medical marijuana laws on workplace fatalities. Our results suggest that legalizing medical marijuana leads to a reduction in workplace fatalities among workers aged 25-44. This reduction may be the result of workers substituting marijuana in place of alcohol and other substances that can impair cognitive function and motor skills; however, it is important to note that we cannot rule out other potential mechanisms. As the debate over legalization of medical and recreational marijuana continues, it is important that we learn more about the effects of MMLs on workplace safety. 


\section{ACKNOWLEDGEMENTS}

Author Contributions: Drs. Anderson and Rees had full access to the data in the study and take responsibility for the integrity of the data and the accuracy of the data analysis.

Study concept and design: Anderson, Rees, Tekin

Acquisition, analysis, or interpretation of data: Anderson, Rees

Drafting of the manuscript: Anderson, Rees, Tekin

Critical revision of the manuscript for important intellectual content: Anderson, Rees, Tekin

Statistical analysis: Anderson

Obtained funding: Anderson

Administrative, technical, or material support: Anderson

Study supervision: Anderson, Rees, Tekin

Conflict of Interest Disclosures: None reported.

Funding/Support: Partial support for this research came from a Eunice Kennedy Shriver

National Institute of Child Health and Human Development research infrastructure grant, R24 HD042828, to the Center for Studies in Demography and Ecology at the University of Washington.

Role of the Funder/Sponsor: The funder had no role in the design and conduct of the study; collection, management, and interpretation of the data; preparation, review, or approval of the manuscript; and decision to submit the manuscript for publication. 


\section{REFERENCES}

1. State Medical Marijuana Laws. National Conference of State Legislatures. http://www.ncsl.org/research/health/state-medical-marijuana-laws.aspx. Updated July 7, 2017. Accessed July 28, 2017.

2. Goldsmith RS, Targino MC, Fanciullo GJ, Martin DW, Hartenbaum NP, White JM, Franklin P. Medical marijuana in the workplace challenges and management options for occupational physicians. J Occup Environ Med. 2015; 57(5):518-525.

3. Parnes JE, Bravo AJ, Conner BT, Pearson MR. A burning problem: cannabis lessons learned from Colorado. Addict Res Theory. In Press.

4. Phillips JA, Holland MG, Baldwin DD, Gifford-Meuleveld L, Mueller KL, Perkison B, Upfal M, Dreger M. Marijuana in the workplace: guidance for occupational health professionals and employers: joint guidance statement of the American Association of Occupational Health Nurses and the American College of Occupational and Environmental Medicine. Workplace Health Saf. 2015; 63(4):139-64.

5. Schwartz ND. Economy needs workers, but drug tests take a toll. New York Times. https://www.nytimes.com/2017/07/24/business/economy/drug-test-labor-hiring.html? r $\mathrm{r}=0$. Published July 24, 2017. Accessed July 28, 2016.

6. Deitchler DL. The workplace and medical marijuana: employer guidelines for navigating the legal haze. Inside Counsel. http://www.insidecounsel.com/2015/04/15/the-workplace-andmedical-marijuana-employer-guide. Updated April 15, 2015. Published July 28, 2017.

7. Hickox SA. Drug testing of medical marijuana users in the workplace: an inaccurate test of impairment. Hofstra Lab \& Emp LJ. 2012; 29(2):273-341.

8. Olafson JJ. Marijuana use and the workplace. Employ Relat Today. 2016; 43(3):67-97.

9. Anderson DM, Hansen B, Rees DI. Medical marijuana laws, traffic fatalities, and alcohol consumption. J Law Econ. 2013; 56(2):333-369.

10. Chu Y. The effects of medical marijuana laws on illegal marijuana use. $J$ Health Econ. 2014; 38(December):43-61.

11. Chu Y. Do medical marijuana laws increase hard-drug use? J Law Econ. 2015; 58(2):481517.

12. Hall W. Adverse health effects of non-medical cannabis use. Lancet. 2009; 374(9698):13831391.

13. Hartman RL, Huestis MA. Cannabis effects on driving skills. Clin Chem. 2013; 59(3):478492. 
14. Marijuana. National Institute on Drug Abuse.

https://www.drugabuse.gov/publications/drugfacts/marijuana. Published February 28, 2017. Accessed July 28, 2017.

15. Ramaekers JG, Berghaus G, van Laar M, Drummer OH. Dose related risk of motor vehicle crashes after cannabis use. Drug Alcohol Depend. 2004; 73(2):109-119.

16. Bachhuber MA, Saloner B, Cunningham CO, Barry CL. Medical cannabis laws and opioid analgesic overdose mortality in the United States, 1999-2010. JAMA Intern Med. 2014; 174(10): 1668-1673.

17. Bradford AC, Bradford WD. Medical marijuana laws reduce prescription medication use in Medicare Part D. Health Affairs. 2016; 35(7):1230-1236.

18. Reiman A. Cannabis as a substitute for alcohol and other drugs. Harm Reduct J. 2009; 6:35.

19. Sabia JJ, Swigert J, Young T. The effect of medical marijuana laws on body weight. Health Econ. 2017; 26(1):6-34.

20. Morantz AD. Has devolution injured American workers? State and federal enforcement of construction safety. J Law Econ Organ. 2009; 25(1):183-210.

21. Smith SM. Workplace hazards of truck drivers. Mon Labor Rev, U.S. Bureau of Labor Statistics. https://doi.org/10.21916/mlr.2015.8. Published April 2015. Accessed July 20, 2017.

22. Mendeloff J, Staetsky L. Occupational fatality risks in the United States and the United Kingdom. Am J Ind Med. 2014; 57(1):4-14.

23. Rosenman K, Kalush A, Reilly MJ, Gardiner JC, Reeves M, Luo Z. How much work-related injury and illness is missed by the current national surveillance system? J Occup Environ Med. 2006; 48(4):357-365.

24. Ruser J. Examining evidence on whether BLS undercounts workplace injuries and illnesses. Mon Labor Rev. 2008; August:20-32

25. Leigh JP, Du J, McCurdy S. An estimate of the U.S. government's undercount of nonfatal occupational injuries and illnesses in agriculture. Ann Epidemiol. 2014; 24(4):254-259.

26. Spieler EA, Wagner GR. Counting matters: implications of undercounting in the BLS survey of occupational injuries and illnesses. Am J Ind Med. 2014; 57(10):1077-1084.

27. Williams AR, Olfson M, Kim JH, Martins SS, Kleber HD. Older, less regulated medical marijuana programs have much greater enrollment rates than newer 'medicalized' programs. Health Aff. 2016; 35(3):480-488. 
28. Selecky M. Patient Access to Medical Marijuana in Washington State. Publication No. 631001. Olympia: Washington State Department of Health.

http://www.doh.wa.gov/portals/1/Documents/2000/PatientAccess.pdf. Published July 2008.

Accessed July 28, 2017.

29. Cameron AC, Trivedi PK. Regression Analysis of Count Data. Cambridge, UK: Cambridge University Press.

30. Bertrand M, Duflo E, Mullainathan S. How much should we trust differences-in-differences estimates? Q J Econ. 2004; 119(1):249-276.

31. Boone J, van Ours JC, Wuellrich J, Zweimüller J. Recessions are bad for workplace safety. $J$ Health Econ. 2011; 30(4):764-773.

32. Scott E. Marijuana Decriminalization. https://www.cga.ct.gov/2010/rpt/2010-R-0204.htm. Updated May 5, 2010. Accessed July 24, 2017.

33. Marijuana Overview. National Conference of State Legislatures.

http://www.ncsl.org/research/civil-and-criminal-justice/marijuana-overview.aspx. Updated April 3, 2017. Accessed July 24, 2017.

34. Local area unemployment statistics. Bureau of Labor Statistics, United States Department of Labor. http://www.bls.gov/lau. Accessed July 15, 2017.

35. Regional economic accounts. Bureau of Economic Analysis, United States Department of Commerce. http://www.bea.gov/regional/index.htm. Accessed July 15, 2017.

36. Anderson DM, Hansen D, Rees DI. Medical marijuana laws and teen marijuana use. Am Law Econ Rev. 2015; 17(2):495-528.

37. Hasin DS, Wall M., Keyes MK, Cerdá M, Schulenberg J, O'Malley PM, Sandro G, Pacula R, Feng T. Medical marijuana laws and adolescent marijuana use in the USA from 1991 to 2014: results from annual, repeated cross-sectional surveys. Lancet Psychiat. 2015; 2(7):601-608.

38. Lynne-Landsman SD, Livingston MD, Wagenaar AC. Effects of state medical marijuana laws on adolescent marijuana use. Am J Public Health. 2013; 103(8):1500-1506.

39. Smart R. The kids aren't alright but older adults are just fine: effects of medical marijuana market growth on substance use and abuse. Available at SSRN:

http://dx.doi.org/10.2139/ssrn.2574915. Published November 25, 2015. Accessed July 31, 2017.

40. Census of Fatal Occupational Injuries Summary, 2015. Bureau of Labor Statistics, United States Department of Labor. https://www.bls.gov/news.release/cfoi.nr0.htm. Published December 16, 2016. Accessed August 1, 2017. 
41. Anderson DM, Rees DI. The legalization of recreational marijuana: how likely is the worstcase scenario? J Policy Anal Manag. 2014; 33(1):221-232.

42. Pacula R., Chriqui J, Reichmann D, Yvonne T. State medical marijuana laws: understanding the laws and their limitations. J Public Health Policy. 2002; 23(4):413-439.

43. Asbridge M, Hayden JA, Cartwright JL. Acute cannabis consumption and motor vehicle collision risk: systematic review of observational studies and meta-analysis. BMJ. 2012; 344: e536.

44. Ohsfeldt RL, Morrisey MA. Beer taxes, workers' compensation, and industrial injury. Rev Econ Statistics. 1997; 79(1):155-160.

45. Ramirez M, Bedford R, Sullivan R., Anthony TR, Kraemer J, Faine B, Peek-Asa C. Toxicology testing in fatally injured workers: a review of five years of Iowa FACE cases. Int $J$ Environ Res Public Health, 2013; 10(11):6154-6168.

46. Zacny, JP. A review of the effects of opioids on psychomotor and cognitive functioning in humans. Exp Clin Psychopharm. 1995; 3(4):432-466.

47. Anderson, DM, Rees DI, Sabia JJ. Medical marijuana laws and suicides by gender and age. Am J Public Health. 2014; 104(12):2369-2376.

48. Morris RG, Teneyck M, Barnes JC, Kovandzic, TV. The effect of medical marijuana laws on crime: evidence from state panel data, 1990-2006. PloS ONE, 2014; 9(3):e92816.

49. Salomonsen-Sautel S, Min S, Sakai, JT, Thurstone C, Hopfera, C. Trends in fatal motor vehicle crashes before and after marijuana commercialization in Colorado. Drug Alcohol Depend. 2014; 140(1 July):137-144.

50. Wen H, Hockenberry J, Cummings JR., The effect of medical marijuana laws on adolescent and adult use of marijuana, alcohol, and other substances. J Health Econ. 2015; 42(July):64-80.

51. Williams AR, Santaella-Tenorio J, Mauro CM, Levin FR, Martin SS. Loose regulation of medical marijuana programs associated with higher rates of adult marijuana use but not cannabis use disorder. Addiction. 2017; 112(11):1985-1991.

52. Ullman DF. The effect of medical marijuana on sickness absence. Health Econ. 2017; 26(10):1322-1327. 
Figure 1. Pre-MML Trends in Workplace Fatalities

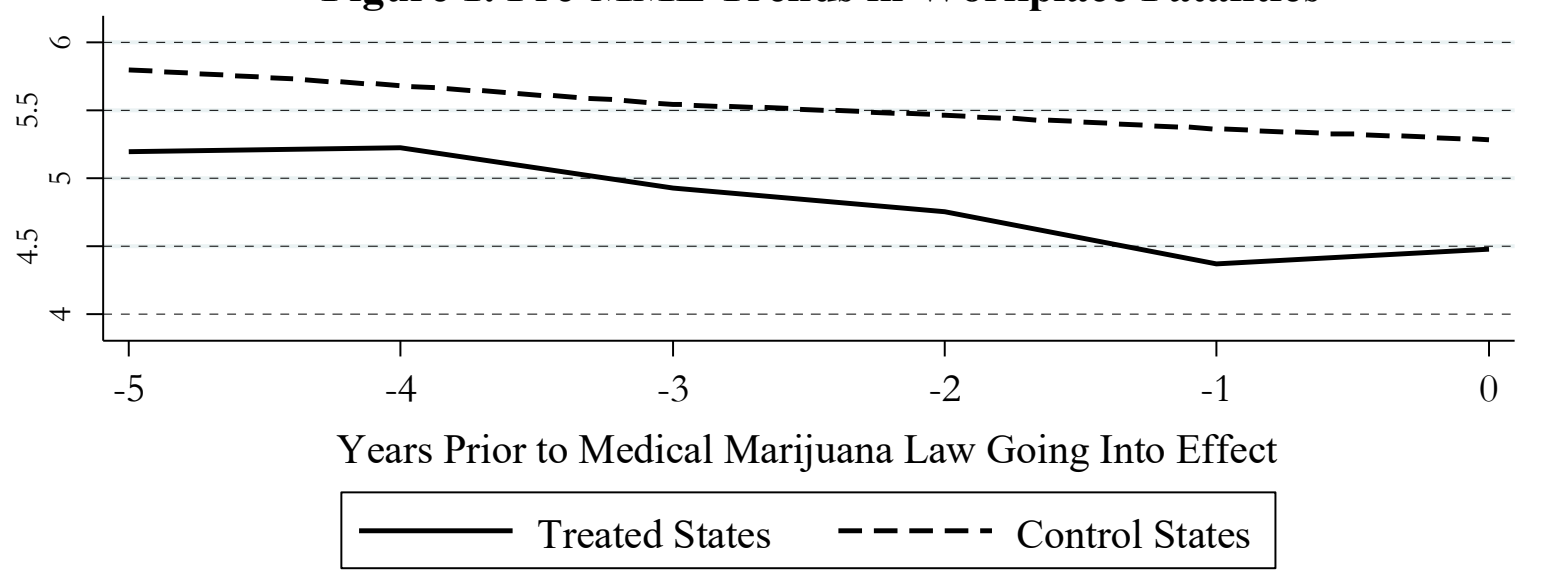

Based on annual data from the Bureau of Labor Statistics. On the horizontal axis, 0 represents the year in which a medical marijuana law went into effect. It was randomly assigned to states that did not legalize medical marijuana during the period under study. 


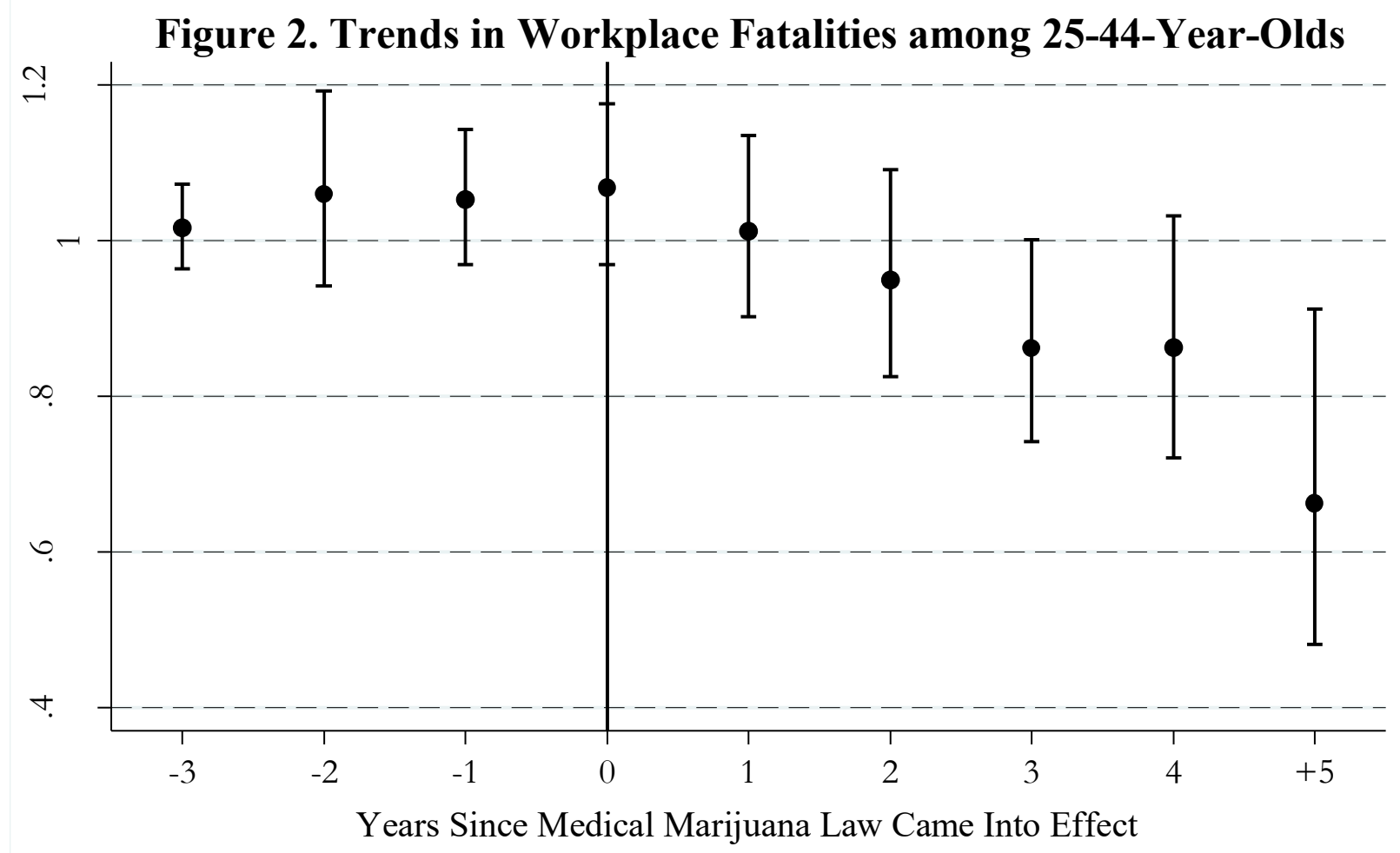

Notes: Incident rate ratios (and their 95\% confidence intervals) from a Poisson regression are reported. The dependent variable is equal to the expected number of workplace fatalities among 25-44-year-olds in state and year $t$. Estimates are adjusted for the covariates listed in Table 2, 50 state indicators, and 23 year indicators. 
Table 1. Medical Marijuana Laws 1992-2015

\begin{tabular}{|c|c|c|c|}
\hline & Effective date & $\begin{array}{c}\text { Pain listed as } \\
\text { qualifying } \\
\text { condition }\end{array}$ & $\begin{array}{c}\text { Collective } \\
\text { cultivation } \\
\text { allowed } \\
\end{array}$ \\
\hline Alaska & March 4, 1999 & Yes & No \\
\hline Arizona & April 14, 2011 & Yes & Yes \\
\hline California & November 6, 1996 & Yes & Yes \\
\hline Colorado & June 1, 2001 & Yes & Yes \\
\hline Connecticut & August $20,2014^{\mathrm{a}}$ & No & No \\
\hline Delaware & June $26,2015^{\mathrm{a}}$ & Yes & No \\
\hline D. C. & July $30,2013^{a}$ & No & No \\
\hline Hawaii & December 28, 2000 & Yes & No \\
\hline Illinois & November $9,2015^{a}$ & No & No \\
\hline Maine & December 22, 1999 & Yes & No \\
\hline Maryland & Passed but not operational ${ }^{b}$ & & \\
\hline Massachusetts & January 1, 2013 & No & No \\
\hline Michigan & December 4, 2008 & Yes & Yes \\
\hline Minnesota & Passed but not operational ${ }^{b}$ & & \\
\hline Montana & November 2, 2004 & Yes & $\mathrm{No}^{\mathrm{c}}$ \\
\hline Nevada & October 1,2001 & Yes & Yes \\
\hline New Hampshire & Passed but not operational ${ }^{b}$ & & \\
\hline New Jersey & December $6,2012^{a}$ & Yes & No \\
\hline New Mexico & July 1, 2007 & No & No \\
\hline New York & Passed but not operational ${ }^{b}$ & & \\
\hline Oregon & December 3, 1998 & Yes & Yes \\
\hline Rhode Island & January 3, 2006 & Yes & Yes \\
\hline Vermont & July 1, 2004 & Yes $^{\mathrm{d}}$ & No \\
\hline Washington & November 3, 1998 & Yes & Yes \\
\hline
\end{tabular}

${ }^{\text {a }}$ Date on which first medical marijuana dispensary opened.

${ }^{\mathrm{b}}$ MML passed during period 1992-2015, but first dispensary did not open until after 2015.

${ }^{\mathrm{c}}$ Prior to Senate Bill 423 (July 1, 2011), Montana allowed for collective cultivation.

d "Pain" added to list of qualifying conditions in 2007. 
Table 2. Descriptive Statistics ${ }^{a}$

Mean

(SD)

Definition

\section{Outcomes}

Total Fatalities

Age 16-24 Fatalities

Age 25-44 Fatalities

Age 45-64 Fatalities

Age 65+ Fatalities

Male Fatalities

Female Fatalities

\section{State-level covariates \\ $M M L$}

$R M L$

Decriminalization

Unemployment

Income

$\%$ White

$\%$ Black

$\%$ Adult
108.3 Total workplace fatalities

(105.3)

8.99 Workplace fatalities among 16-24-year-olds

(11.9)

45.0 Workplace fatalities among 25-44-year-olds

41.5

(39.2)

10.6

100.0 Workplace fatalities among male workers

$(97.5)$

8.34

$(8.70)$

Workplace fatalities among 45-64-year-olds

Workplace fatalities among 65+ year-olds

Workplace fatalities among female workers

$158=1$ if state legalized marijuana for medicinal

(.362) use, $=0$ otherwise

$.003=1$ if state has legalized marijuana for

(.052) recreational use, $=0$ otherwise

$.243=1$ if state decriminalized marijuana, $=0$

(.428) otherwise

5.69 State unemployment rate

(1.89)

37,817 State real income per capita (2010 dollars)

$(7,188)$

.822 Percent of state population white

.117

.752

$(.023)$

$\mathrm{N}=1,224$

\footnotetext{
${ }^{\text {a }}$ Unweighted means (with standard deviations in parentheses) are reported.
} 
Table 3. Estimates of Relationship between Legalizing Medical Marijuana and Workplace Fatalities ${ }^{\text {a }}$

\begin{tabular}{cccccccc} 
& Total & Ages 16-24 & Ages 25-44 & Ages 45-64 & Ages 65+ & Male & $\begin{array}{c}\text { Female } \\
\text { Fatalities }\end{array}$ \\
& Fatalities & Fatalities & Fatalities & Fatalities & Fatalities & Fatalies \\
\hline MML & .868 & .946 & $\mathbf{. 8 0 5}$ & .894 & .986 & .885 & .772 \\
& {$[.712,1.06]$} & {$[.786,1.14]$} & {$[.662, .979]$} & {$[.728,1.10]$} & {$[.746,1.30]$} & {$[.728,1.07]$} & {$[.592,1.01]$} \\
\hline
\end{tabular}

Boldface indicates statistical significance $(p<0.05)$

${ }^{a}$ Each cell reports an incidence rate ratio (IRR) from a separate Poisson regression based on data from the Bureau of Labor Statistics (1992-2015). All regressions are weighted by state employment for the relevant population. IRRs are adjusted for the state characteristics listed in Table 2, 50 state indicators, and 23 year indicators. Ninety-five \% confidence intervals are in brackets. $\mathrm{N}=$ 1,224 . 
Table 4. Medical Marijuana Laws and Workplace Fatalities among 25-44Year-Olds by Whether Pain was a Qualifying Condition and Whether Collective Cultivation was Allowed ${ }^{\text {a }}$

\begin{tabular}{lc} 
Panel I & Ages $25-44$ Fatalities \\
\hline$M M L-$ Pain Qualifying Condition & $\mathbf{. 8 0 2}$ \\
& {$[\mathbf{. 6 5 7}, \mathbf{9 7 8}]$} \\
$M M L-$ Pain Not Qualifying Condition & .980 \\
& {$[.859,1.12]$}
\end{tabular}

\section{Panel II}

$M M L$ - Collective Cultivation Allowed

MML - Collective Cultivation Prohibited

Boldface indicates statistical significance $(p<0.05)$
Ages 25-44 Fatalities

.795

$[.651, .971]$

1.03

$[.832,1.27]$

${ }^{a}$ Each panel reports IRRs from a separate Poisson regression based on data from the Bureau of Labor Statistics (1992-2015). All regressions are weighted by state employment for the population of 25-44-year-olds. IRRs are adjusted for the state characteristics listed in Table 2, 50 state indicators, and 23 year indicators. Ninety-five \% confidence intervals are in brackets. $\mathrm{N}=1,224$. 